\title{
Evaluation of Nosocomial Infections and Their Relationships with Demographic Data in Four Different Intensive Care Units of an Education and Research Hospital
}

\author{
Ibrahim Gezgel ${ }^{1} \cdot$ Yucel Yuce $^{2}$ (D) $\cdot$ Tamer Kuzucuoglu $^{2} \cdot$ Kutlu Hakan Erkal $^{2} \cdot$ Banu Cevik $^{2} \cdot$ Recep Demirhan $^{3}$
}

Accepted: 11 October 2019 / Published online: 13 November 2019

(C) Springer Nature Switzerland AG 2019

\begin{abstract}
In all units where health care is provided, especially in intensive care units, infection-related complications are conditions that increase the cost and complicate the treatment process. In our study, in 2014-2015, the Ministry of Health Kartal Dr. Data of 1204 patients followed up in intensive care units of Lutfi Kirdar Training and Research Hospital were analyzed. We excluded the patients with antibiotic therapy at admission to the intensive care unit. Cases followed up in the intensive care unit for less than 24 $\mathrm{h}$, and cases with culture detected in the first $48 \mathrm{~h}$ were also excluded from the study. Data from 287 patients with culture-positive infections of 743 patients who met the study admission criteria were analyzed. In diagnosing infectious diseases, laboratoryproven blood circulation infections were grouped as catheter-related urinary tract, central venous catheter-related bloodstream infection, ventilator-associated pneumonia, and burn infection. The hospital infections detected in our intensive care units and the determination of the causative pathogens were evaluated according to the differences in these infections according to years, units, diagnoses, demographic data, and clinical presentations. It was determined that hospitalization diagnoses, presence of comorbid diseases, and the percentage of burns were firmly related to the duration of ICU stay and mortality. Acinetobacter baumannii infections were significantly higher in our intensive care units compared with other microorganisms. We aimed to evaluate the data of the patients who were followed up in intensive care units of Dr. Lutfi Kirdar Kartal Training and Research Hospital between 2014 and 2015 with culture-positive infection retrospectively.
\end{abstract}

Keywords Nosocomial $\cdot$ Infection $\cdot$ Intensive care $\cdot$ Culture

\section{Introduction}

Hospital infection is a significant cause of mortality and morbidity all over the world (1). Although it is not present at the time of admission to the hospital, they develop after $48-72 \mathrm{~h}$

This article is part of the Topical Collection on Medicine

Yucel Yuce

dryyuce@gmail.com

Ibrahim Gezgel

igezgel@gmail.com

Tamer Kuzucuoglu

tkuzucuoglu@hotmail.com

Kutlu Hakan Erkal

hakerkal@hotmail.com

Banu Cevik

banucevik17@gmail.com after hospitalization. Besides, their findings can occur after discharge (2).

Intensive care unit (ICU) beds account for about $10 \%$ of all beds in the hospital, but infections in intensive care units account for $20-25 \%$ of all hospital infections (3). Patients

Recep Demirhan

rdemirhan@yahoo.com

1 Kartal Kosuyolu Education and Research Hospital, Anesthesiology and Reanimation Clinic, University of Health Sciences, İstanbul, Turkey

2 Kartal Dr. Lütfi Kurdar Education and Research Hospital, Anesthesiology and Reanimation Clinic, University of Health Sciences, İstanbul, Turkey

3 Kartal Dr. Lutfi Kurdar Education and Research Hospital, Thoracic Surgery Clinic, University of Health Sciences, Istanbul, Turkey 
followed in the intensive care unit form the patient group with a broad spectrum of antibiotics, including one or more organ failure, as well as primary disease-threatening primary diseases, and every type of medical surgery and invasivenoninvasive monitoring techniques are frequently used. Therefore, ICU-monitored patients are critical patients who are more susceptible to nosocomial infections, and the development of ICU infections is a significant cause of mortality and morbidity (4).

We aimed to determine the hospital infections and pathogens detected in the reanimation units of Dr. Lutfi Kirdar Kartal Training and Research Hospital, and we evaluated the relationships with demographic data retrospectively.

\section{Material and Method}

After obtaining Institutional Review Board approval, we retrospectively reviewed all medical records of the patients who were followed in the Intensive Care Unit of Dr. Lutfi Kirdar Kartal Training and Research Hospital between January 1, 2014, and December 31, 2015. Also, a statement on informed consent from the parents/Legally Authorized Representatives of participants was obtained. Infectious diseases and clinical microbiology infection registry databases were examined in detail. The patients who were diagnosed with a culture-positive infection in intensive care units were determined. Cases followed up in the intensive care unit for less than $24 \mathrm{~h}$ and patients with culture detected in the first $48 \mathrm{~h}$ were also excluded from the study.

Age, gender, diagnosis group, diagnosis, comorbid disease, hospitalization time, Glasgow Coma Scale (GCS), APACHE II score, microorganism, location of infection and differential diagnosis, presence of a catheter, and site of the catheter if there is a demographic data were scanned in detail. Complete blood count results obtained on the day of the culture of the patients were noted.

\section{Statistical Analysis}

When evaluating the findings obtained in this study, IBM SPSS Statistics 22 for statistical analysis (SPSS IBM, Turkey) programs were used. The fit of the parameters to normal distribution was evaluated by Shapiro Wilks test. In the evaluation of the data, descriptive statistical methods (mean, standard deviation, frequency), as well as comparison of quantitative data, were used.

The Kruskal Wallis test was used to compare the parameters that did not show normal distribution. MannWhitney $U$ test was used to determine the difference group. Student's $t$ test was used to distinguish normal distribution parameters, and the Mann-Whitney $U$ test was used to compare the settings that did not show normal distribution. Chi-square test, Fisher acts exact test, and Continuity (Yates) Correction were used to analyze qualitative data. Spearmanesindes Rho correlation analysis was used to examine the relationships between the parameters. Significance was evaluated at $p<0.05$.

\section{Results}

A total of 287 patients (184 male (64.1\%) were male, and 103 (35.9\%) were female. The age of the patients ranged from 0 to 97 , and the mean was $54.37 \pm 23.34$. The hospitalization period ranged from 3 to 274 days, with a mean of $56.86 \pm 52.29$. $64.1 \%$ of the cases were male, and $35.9 \%$ were female (Table 1).

While $37.6 \%$ of patients had no additional disease, $26.8 \%$ had $1,26.5 \%$ had 2 , and $9.1 \%$ had 3 additional diseases. $34.8 \%$ of existing additional diseases are cardiovascular, $30.3 \%$ endocrine, $13.2 \%$ neurological, $10.5 \%$ malignancy, $9.8 \%$ respiratory, $7.7 \%$ renal, and $0.7 \%$ gastrointestinal disease.

$87.1 \%$ of the cases were intubated, $\mathrm{O} 2$ masked $9.4 \%$, and the tracheostomy rate was $3.5 \%$. While $34.8 \%$ were diagnosed as burn, $18.1 \%$ had neurological, $16.7 \%$ had respiratory, $12.2 \%$ had trauma, $9.4 \%$ had malignancy, $3.1 \%$ had gastrointestinal disease, $3.1 \%$ had another diagnosis, and $2.4 \%$ had renal disease (Table 2 ).

$48.1 \%$ of patients had laboratory-proven bloodstream infection, $22 \%$ had ventilator-associated pneumonia, $15.7 \%$ had burn infection, $8.4 \%$ had catheter-associated urinary tract infection, and $4.9 \%$ had central venous catheter-associated bloodstream infection. $1 \%$ had decubitus ulcer infection.

$30.7 \%$ of the cases were operated. While $38.6 \%$ of the operated patients underwent a neurosurgical emergency operation, $27.3 \%$ were burn emergency operations. $21.6 \%$ were GIS emergency, $8 \%$ were an orthopedic emergency, and $4.5 \%$ were in other types of surgery. The exitus rate was $60.6 \%$, and $39.4 \%$ were discharged from the intensive care unit (Table 3 ).

Acinetobacter baumannii in $36.2 \%$, Pseudomonas in $16.4 \%$, Klebsiella pneumoniae in $9.1 \%$, Candida parapsilosis

Table 1 Evaluation of demographic characteristics of the cases

\begin{tabular}{lll}
\hline & Min-Max & Mean \pm SD \\
\hline Age (year) & $0-97$ & $54.37 \pm 23.34$ \\
Length of hospital stay (day) & $3-274$ & $56.86 \pm 52.29$ \\
& $\boldsymbol{n}$ & $\%$ \\
Gender & & \\
Male & 184 & 64.1 \\
Female & 103 & 35.9 \\
\hline
\end{tabular}


Table 2 Distribution of additional disease-related parameters

\begin{tabular}{lll}
\hline & $n$ & $\%$ \\
\hline Additional disease & & \\
+ & 179 & 62.4 \\
- & 108 & 37.6 \\
Number of additional disease & & \\
0 & 108 & 37.6 \\
1 & 77 & 26.8 \\
2 & 76 & 26.5 \\
3 & 26 & 9.1 \\
Endocrine & 87 & 30.3 \\
Gastrointestinal & 2 & 0.7 \\
Neurologic & 38 & 13.2 \\
Cardiovascular & 100 & 34.8 \\
Malignity & 30 & 10.5 \\
Respiratory & 28 & 9.8 \\
Renal & 22 & 7.7 \\
\hline
\end{tabular}

in $8.7 \%$, coagulase-negative staphylococcus in $8.4 \%$, Candida albicans in 6.3\%, Staphylocoscus aureus in $4.2 \%$, Escherichia coli in $4.2 \%$, Proteus mirabilis in $2.8 \%$, and other microorganisms in $4.2 \% .55 .1 \%$ of the patients were started with 2 antibiotics, $35.5 \%$ were started with 1 antibiotic and $9.4 \%$ with 3 or more antibiotics. The incidence of central venous catheter was $42.2 \%$ femoral, $30.3 \%$ was subclavian, and $27.5 \%$ was jugular.

Table 3 Evaluation of parameters related to infection and surgery

\begin{tabular}{|c|c|c|c|c|c|}
\hline & $n$ & $\%$ & $\begin{array}{l}\text { was } 9.96 \pm \\
\text { an average }\end{array}$ & $\begin{array}{l}\text { APACHE value } \\
18 \pm 5.32 . \text { The V }\end{array}$ & $\begin{array}{l}\text { ed from } 10 \text { to } 31 \text {, with } \\
\text { alues ranged between }\end{array}$ \\
\hline Infection & & & 2000 and 1 & 0, and the mean & $2,894.91 \pm 10,872.67$ \\
\hline Decubitus ulcer infection & 3 & 1 & HBG value & ged from 5.4 to $1<$ & d the mean was $9.43 \pm$ \\
\hline Catheter-associated urinary tract infection & 24 & 8.4 & 1.47. HCT & s ranged from 1 & 286 , with a mean of \\
\hline Laboratory-proven bloodstream infection & 138 & 48.1 & & & \\
\hline Central venous catheter-associated bloodstream infection & 14 & 4.9 & & & \\
\hline Ventilator-associated pneumonia & 63 & 22 & Table 5 & n of the laboratory & eters \\
\hline Burn infection & 45 & 15.7 & & Min-Max & Mean $\pm \mathrm{SD}$ \\
\hline $\begin{array}{l}\text { Surgical intervention } \\
+\end{array}$ & 88 & 30.7 & GCS & $3-15$ & $9.96 \pm 2.68$ \\
\hline- & 199 & 69.3 & APACHE II & $10-31$ & $19.18 \pm 5.32$ \\
\hline Surgical intervention $(n=88)$ & & & WBC & $2000-151,000$ & $12,894.91 \pm 10,872.67$ \\
\hline GIS emergency & 19 & 21.6 & HGB & $5.4-14.8$ & $9.43 \pm 1.47$ \\
\hline Neurosurgical emergency & 34 & 38.6 & HCT & $15.1-286$ & $29.51 \pm 15.81$ \\
\hline Orthopedic emergency & 7 & 8 & PLATELET & $14,000-1,027,000$ & $265,982.58 \pm 158,112.44$ \\
\hline Burn emergency & 24 & 27.3 & MPV & $5.6-15.5$ & $8.84 \pm 1.65$ \\
\hline Other & 4 & 4.5 & PDV & 14.2-199. & $17.36 \pm 0.83$ \\
\hline Mortality & & & $\mathrm{NEU}$ & $0.1-53$ & $9.84 \pm 6.57$ \\
\hline Exitus & 174 & 60.6 & LYM & $0.2-7.5$ & $1.39 \pm 1.04$ \\
\hline Discharge & 113 & 39.4 & MON & $0-9.6$ & $0.66 \pm 0.77$ \\
\hline
\end{tabular}

Table 4 Distribution of microorganism, antibiotic number, catheter location and tracheostomy parameters

\begin{tabular}{lll}
\hline & $n$ & $\%$ \\
\hline Microorganism & & \\
Acinetobacter baumannii & 104 & 36.2 \\
Candida albicans & 18 & 6.3 \\
Candida parapsilosis & 25 & 8.7 \\
Escherichia coli & 11 & 3.8 \\
Klebsiella pneumoniae & 26 & 9.1 \\
Koagülaz negatif stafilokok & 24 & 8.4 \\
Proteus mirabilis & 8 & 2.8 \\
Pseudomonas aeruginosa & 47 & 16.4 \\
Staphylococcus aureus & 12 & 4.2 \\
Other & 12 & 4.2 \\
Number of antibiotics & & \\
1 & 102 & 35.5 \\
2 & 158 & 55.1 \\
3 and more & 27 & 9.4 \\
Catheter site & & \\
Femoral & 121 & 42.2 \\
Juguler & 79 & 27.5 \\
Subclavian & 87 & 30.3 \\
\hline
\end{tabular}

$55.1 \%$ of the patients were started with two antibiotics, $35.5 \%$ were begun with one antibiotic, and $9.4 \%$ with 3 or more antibiotics. The incidence of the central venous catheter was $42.2 \%$ femoral, $30.3 \%$ was subclavian, and $27.5 \%$ was jugular (Table 4).

GCS values of the cases ranged from 3 to 15 , and the mean was $9.96 \pm 2.68$. APACHE values ranged from 10 to 31 , with an average of $19.18 \pm 5.32$. The WBC values ranged between 2000 and 151,000, and the mean was 12,894.91 $\pm 10,872.67$. HBG values ranged from 5.4 to 14.8 , and the mean was $9.43 \pm$ 1.47. HCT values ranged from 15.1 to 286 , with a mean of

Table 5 Evaluation of the laboratory parameters 
$29.51 \pm 15.81$. Platelet values ranged from 14,000 to $1,027,000$, and the average was $265,982.58 \pm 158,112.44$.

The MPV values of the cases ranged from 5.6 to 15.5 , and the mean was $8.84 \pm 1.65$. The PDV values ranged from 14.2 to 19.9 , with an average of $17.36 \pm 0.83$. The number of monocytes (MON) ranged from 0 to 9.6 , with an average of $0.66 \pm 0.77$. There was no statistically significant difference between the distribution rates of the patients according to years $(p, 0.109 ; p>0.05)$ (Table 5).

There was a statistically significant difference between the distribution rates of the diagnoses $(p, 0.038 ; p<0.05)$. The proportion of cases diagnosed as gastrointestinal in $2014(0 \%)$ was lower than the rate of cases in 2015 (5.8\%), while the percentage of cases diagnosed as neurologic in 2014 $(14.3 \%)$ was statistically lower than the rate of cases in 2015 (21.4\%) (Table 6).

There was a statistically significant difference between the mean age of the patients according to the intensive care unit $(p, 0.007 ; p<0.05)$. The mean age of the patients in the burn intensive care unit was found to be significantly lower than the mean of the patients in the second level, emergency and central intensive care units $(p, 0.001 ; p<0.05)$. There was no statistically significant difference in the mean age of the patients between the emergency, central, and second order intensive care units $(p>0.05)$.

There was a statistically significant difference between the mean duration of hospitalization of the patients according to the intensive care unit $(p, 0.001 ; p<0.05)$. The mean duration of hospital stay in the ICU was found to be significantly higher $(p<0.05)$. The mean duration of hospitalization of the patients who came to the burn intensive care unit was found to be considerably lower than the mean of the patients in emergency and central intensive care units $(p, 0.001 ; p<0.05)$. There was no statistically significant difference in the mean duration of hospitalization between the emergency and central intensive care units $(p>0.05)$.

There was a statistically significant difference between the APACHE II averages of the patients according to the ICU ( $p$, $0.001 ; p<0.05)$. APACHE II averages of patients who came to burn intensive care unit were found to be significantly lower than the proportion from patients in the 2nd level, emergency and central intensive care units $(p, 0.001 ; p<0.05)$. There was no statistically significant difference in APACHE II averages among the other intensive care units $(p>0.05)$.

There was a statistically significant difference between the mortality distribution rates of the patients according to the intensive care unit $(p, 0.001 ; p<0.05)$. The incidence of exincidence was significantly lower in the patients who were admitted to the intensive care unit (32\%), 2nd level (79.1\%), emergency $(76.6 \%)$, and central $(73.1 \%)$ intensive care units $(p, 0.001 ; p<0.05)$. There was no statistically significant difference between the other intensive care units $(p>0.05)$ (Table 7).

There was no statistically significant difference between the microorganism distribution rates of the cases according to the intensive care unit $(p>0.05)$. There was a statistically significant difference between the microorganism distribution rates of the cases according to the type of infection $(p, 0.001 ; p$ $<0.05)$. The rate of Acinetobacter baumannii in patients with catheter-related urinary tract infection was statistically
Table 6 Evaluation of type of infection and diagnostic parameters by year

\begin{tabular}{llll}
\hline & Year & & \\
& & & \\
& 2014 & 2015 \\
& $n(\%)$ & $n(\%)$ \\
\hline Infection type & & \\
Catheter-associated urinary tract infection & $12(9)$ & $12(7.8)$ & 0.109 \\
Laboratory-proven bloodstream infection & $71(53.4)$ & $67(43.5)$ & \\
Central venous catheter-associated bloodstream infection & $7(5.3)$ & $10(6.5)$ \\
Ventilator-associated pneumonia & $20(15)$ & $43(27.9)$ \\
Burn infection & $23(17.3)$ & $22(14.3)$ \\
Diagnosis & & \\
Gastrointestinal & $0(0)$ & $9(5.8)$ \\
Malignity & $16(12)$ & $11(7.1)$ \\
Neurologic & $19(14.3)$ & $33(21.4)$ \\
Renal & $5(3.8)$ & $2(1.3)$ \\
Respiratory & $22(16.5)$ & $26(16.9)$ \\
Trauma & $15(11.3)$ & $20(13)$ \\
Burn & $52(39.1)$ & $48(31.2)$ \\
Other & $4(3)$ & $5(3.2)$ \\
\hline
\end{tabular}

Chi-square test, $* p<0.05$ 
Table 7 Evaluation of age, length of stay, gender, and mortality parameters by ICU

\begin{tabular}{|c|c|c|c|c|c|}
\hline & \multicolumn{4}{|c|}{ Type of intensive care unit } & \multirow[t]{2}{*}{$p$} \\
\hline & $\begin{array}{l}\text { 2. level } \\
\text { Mean } \pm \text { SD }\end{array}$ & $\begin{array}{l}\text { Emergency } \\
\text { Mean } \pm \text { SD }\end{array}$ & $\begin{array}{l}\text { Central } \\
\text { Mean } \pm \text { SD }\end{array}$ & $\begin{array}{l}\text { Burn } \\
\text { Mean } \pm \text { SD }\end{array}$ & \\
\hline Age (year) & $63.86 \pm 18.54$ & $61.97 \pm 21.06$ & $63.75 \pm 18.64$ & $38.14 \pm 2112$ & ${ }^{1} 0.007 *$ \\
\hline Length of hospital stay (median) & $80.05 \pm 64.82(63)$ & $63.66 \pm 65.07(45)$ & $53.4 \pm 29.84(52)$ & $43.97 \pm 42.75(27.5)$ & ${ }^{2} 0.001 *$ \\
\hline APACHE II (median) & $\begin{array}{l}21.93 \pm 4.37(22) \\
\boldsymbol{n}(\%)\end{array}$ & $\begin{array}{l}21.05 \pm 5.27(21) \\
\boldsymbol{n}(\%)\end{array}$ & $\begin{array}{l}20.54 \pm 4.97(21) \\
\boldsymbol{n}(\%)\end{array}$ & $\begin{array}{l}15.66 \pm 4.02(15) \\
\boldsymbol{n}(\%)\end{array}$ & ${ }^{2} 0.001$ * \\
\hline \multicolumn{6}{|l|}{ Gender } \\
\hline $\begin{array}{l}\text { Male } \\
\text { Female }\end{array}$ & $\begin{array}{l}33(76.7) \\
10(23.3)\end{array}$ & $\begin{array}{l}42(54.5) \\
35(45.5)\end{array}$ & $\begin{array}{l}43(64.2) \\
24(35.8)\end{array}$ & $\begin{array}{l}66(66) \\
34(34)\end{array}$ & ${ }^{3} 0.102$ \\
\hline \multicolumn{6}{|l|}{ Mortality } \\
\hline $\begin{array}{l}\text { Ex } \\
\text { Discharge }\end{array}$ & $\begin{array}{l}34(79.1) \\
9(20.9)\end{array}$ & $\begin{array}{l}59(76.6) \\
18(23.4)\end{array}$ & $\begin{array}{l}49(73.1) \\
18(26.9)\end{array}$ & $\begin{array}{l}32(32) \\
68(68)\end{array}$ & ${ }^{3} 0.001$ * \\
\hline
\end{tabular}

${ }^{1}$ One-way ANOVA

${ }^{2}$ Kruskal-Wallis test

${ }^{3}$ Chi-square test

$* p<0.05$

significantly lower than those with laboratory-proven blood circulation $(p, 0.001)$ and ventilator-associated pneumonia $(p$, 0.002), whereas Escherichia coli was found to be higher $(p<$ $0.05)$.

The rate of Acinetobacter baumannii reproduced in patients with ventilator-associated pneumonia infection was statistically significantly higher than those of laboratoryproven blood circulation $(p, 0.006)$ and burn $(p, 0.029)$ infection, whereas Candida parapsilosis rate was found to be low $(p<0.05)$. There was no statistically significant difference between the infection types in terms of the distribution of microorganisms in the cases $(p>0.05)$ (Tables 8 and 9).

\section{Discussion}

Intensive care units are among the clinics where nosocomial infections are seen most in hospitals. Given the fact that $53.6 \%$ of nosocomial infections in the ICU resulted in death, the importance of prevention of these infections is better understood (5). Invasive procedures for diagnosis and treatment (mechanical ventilation, central and urinary catheter, vascular pathways, cardiovascular monitoring, etc.) together with the patients' underlying diseases and medicines (sedatives, antacids, H2 receptor antagonists, immunosuppressive medications) weaken the defense system of the patients. They increase the risk of hospital-acquired infection (6).
Table 8 Evaluation of microorganisms grown by intensive care unit

\begin{tabular}{|c|c|c|c|c|c|}
\hline \multirow[t]{2}{*}{ Type of microorganism } & \multicolumn{4}{|c|}{ Type of intensive care unit } & \multirow[t]{2}{*}{$p$} \\
\hline & $\begin{array}{l}\text { 2. level } \\
n(\%)\end{array}$ & $\begin{array}{l}\text { Emergency } \\
n(\%)\end{array}$ & $\begin{array}{l}\text { Central } \\
n(\%)\end{array}$ & $\begin{array}{l}\text { Burn } \\
n(\%)\end{array}$ & \\
\hline Acinetobacter baumannii & $15(34.8)$ & $37(48.1)$ & $26(38.8)$ & $31(31)$ & 0.499 \\
\hline Candida albicans & $2(4.7)$ & $5(6.5)$ & $3(4.5)$ & $8(8)$ & \\
\hline Candida parapsilosis & $4(9.3)$ & $9(11.7)$ & $5(7.5)$ & $7(7)$ & \\
\hline Escherichia coli & $2(4.6)$ & $1(1.3)$ & $3(4.5)$ & $3(3)$ & \\
\hline Klebsiella pneumoniae & $5(11.6)$ & $3(3.9)$ & $5(7.5)$ & $13(13)$ & \\
\hline Koagülaz negatif stafilokok & $4(9.3)$ & $4(5.2)$ & $8(11.9)$ & $8(8)$ & \\
\hline Proteus mirabilis & $2(4.7)$ & $1(1.3)$ & $1(1.5)$ & $4(4)$ & \\
\hline Pseudomonas aeruginosa & $6(13.9)$ & $10(13)$ & $11(16.4)$ & $17(17)$ & \\
\hline Staphylococcus aureus & $2(4.7)$ & $2(2.6)$ & $4(6)$ & $4(4)$ & \\
\hline Diğer & $1(2.3)$ & $5(6.5)$ & $1(1.5)$ & $5(5)$ & \\
\hline
\end{tabular}

Chi-square test, $* p<0.05$ 
Table 9 Evaluation of growth microorganisms by type of infection

\begin{tabular}{|c|c|c|c|c|c|}
\hline \multirow{2}{*}{$\begin{array}{l}\text { Type of } \\
\text { microorganism }\end{array}$} & \multicolumn{5}{|l|}{ Type of infection } \\
\hline & $\begin{array}{l}\text { Catheter-associated } \\
\text { urinary tract } \\
n(\%)\end{array}$ & $\begin{array}{l}\text { Laboratory-proven } \\
\text { bloodstream } \\
n(\%)\end{array}$ & $\begin{array}{l}\text { Central venous catheter-associated } \\
\text { bloodstream } \\
n(\%)\end{array}$ & $\begin{array}{l}\text { Ventilator-associated } \\
\text { pneumonia } \\
n(\%)\end{array}$ & $\begin{array}{l}\text { Burn } \\
n(\%)\end{array}$ \\
\hline $\begin{array}{c}\text { Acinetobacter } \\
\text { baumannii }\end{array}$ & $5(20.8)$ & $43(31.2)$ & $12(70.6)$ & $33(52.4)$ & $11(24.4)$ \\
\hline Candida albicans & $0(0)$ & $13(9.4)$ & $0(0)$ & $1(1.6)$ & $4(8.9)$ \\
\hline Candida parapsilosis & $2(8.3)$ & $17(12.3)$ & $1(5.9)$ & $1(1.6)$ & $4(8.9)$ \\
\hline Escherichia coli & $7(29.2)$ & $2(1.4)$ & $0(0)$ & $1(1.6)$ & $1(2.2)$ \\
\hline $\begin{array}{l}\text { Klebsiella } \\
\text { pneumoniae }\end{array}$ & $1(4.2)$ & $11(8)$ & $2(11.8)$ & $6(9.5)$ & $6(13.3)$ \\
\hline $\begin{array}{l}\text { Coagulase }(-) \\
\text { staphylococcus }\end{array}$ & $1(4.2)$ & $18(13)$ & $0(0)$ & $2(3.2)$ & $3(6.7)$ \\
\hline Proteus mirabilis & $1(4.2)$ & $4(2.9)$ & $0(0)$ & $0(0)$ & $3(6.7)$ \\
\hline $\begin{array}{r}\text { Pseudomonas } \\
\text { aeruginosa }\end{array}$ & $4(16.7)$ & $20(14.5)$ & $1(5.9)$ & $15(23.8)$ & $7(15.6)$ \\
\hline $\begin{array}{l}\text { Staphylococcus } \\
\text { aureus }\end{array}$ & $1(4.2)$ & $6(4.3)$ & $0(0)$ & $2(3.2)$ & $3(6.7)$ \\
\hline Other & $2(8.3)$ & $4(2.9)$ & $1(5.9)$ & $2(3.2)$ & $3(6.7)$ \\
\hline
\end{tabular}

Chi-square test, $* p<0.05$

In the studies conducted in the world and our country, the source of intensive care infections, agent types, and antibiotic resistance are different (7). It is seen that infectious agents vary between countries and even between units in the same region. Antibiotic resistance of agents varies, and those hospitalrelated infections are affected by many factors, and there may be ethical problems in generalizing the results of surveillance studies (8).

In a study conducted in Turkey and published in 2002, hospital infections detected in an intensive care unit of a university hospital were evaluated (9). In this study, nosocomial pneumonia was the first in $37.1 \%$, followed by sepsis with $33.5 \%$, urinary tract infection with $20 \%$, surgical site infection with $8 \%$, and diseases in other regions with $1.2 \%$.

In our study, laboratory-proven blood circulation infection was found in $48.1 \%$ of the cases, ventilator-associated pneumonia in $22 \%$, burn infection in $15.7 \%$, catheter-related urinary tract infection in $8.4 \%$, and central venous catheterrelated blood in $4.9 \%$. In our study, the low rate of ventilator-associated pneumonia is remarkable. Again, proven blood circulation infection and central venous catheter-related bloodstream infections are higher than other studies.

The difference in source and type of infection between studies is remarkable. This difference can be explained by many factors such as the physical conditions of intensive care units, the diversity of patients admitted and followed, and the policy differences in infection control (9). Besides, increasing measures to combat ventilator-associated pneumonia in intensive care units and increasing awareness of clinicians and nursing care providers may be one of the factors affecting this situation.
In a university hospital medical faculty intensive care unit, the most commonly isolated Gram-negative rod was Pseudomonas spp. 19\% E.coli, 16\% Acinetobacter spp., $14 \%$ Klebsiella spp., and $12 \%$ other Gram-negative rods (Citrobacter spp., Enterobacter spp., Proteus spp., and Serratia spp.) have been reported (10).

In our study, the distribution of the organisms was $36.2 \%$ Acinetobacter baumannii, 16.4\% Pseudomonas, 9.1\% Klebsiella pneumonia, $8.7 \%$ Candida parapsilosis, $8.4 \%$ coagulase-negative staphylococci, $6.3 \%$ Candida albicans, 4.2\% Staphylococcus aureus, and 3.8\% Escherichia coli and Proteus mirabilis (2.8\%), and other microorganisms (4.2\%). Compared with other studies, it is seen that the isolated agents in intensive care units and their frequency vary greatly. In most studies, the most commonly remote agent was Pseudomonas or Staphylococcus aureus, whereas, in our study, the rate of Acinetobacter baumannii was as high as $36.2 \%$. This difference may be due to the differences in intensive care units where the reviews are performed and the patient profile and the demographic characteristics of the patients. Besides, patients may be affected by diagnostic groups and surgical procedures, such as transfer from another ward, and agent transfer between departments or intensive care units is a common occurrence. It may be expected that our results will differ from other conflicts.

Infectious disease clinics did most of the studies that we mentioned, and they looked at the facts from their scientific perspectives. In our study, we did not address antibiotic resistance. Instead, we made an assessment based on the number of antibiotics initiated in line with recommendations for infectious diseases. $55.1 \%$ of the cases were started with two 
antibiotics, $35.5 \%$ with one antibiotic, and $9.4 \%$ with 3 or more antibiotics. Two or more medicines initiated in majority of the cases show both the hepatic-renal risks of the patients and the cost of antibiotics in the ICU patients. It is the antibiotic resistance that makes infectious disease physicians start such multiple antibiotics.

In general, studies have evaluated units such as chest diseases intensive care, internal intensive care, and surgical intensive care. We assessed all 2nd level, emergency, central, and burn intensive care units in our hospital. When we evaluate these data, the age of the culture-positive patients in the burn intensive care unit was younger than the other groups. The duration of hospitalization in the burn intensive care unit was shorter, and the mean APACHE II scores were higher in the burn intensive care unit patients. Besides, mortality was $70-80 \%$ in the other units, and $32 \%$ in culture-positive patients followed in the burn intensive care unit. These conditions may be caused by differences in demographic data such as age and comorbidities of patients admitted to burn intensive care unit. Also, the fact that all patients are being followed up in isolated rooms in our burn intensive care unit is one of the factors that decrease mortality. We found that the length of stay in the second level intensive care unit was longer. This situation may be since end-aged elderly patients are being followed up in the second level intensive care unit of our hospital.

When we evaluated the diagnosis of infection, the rate of ventilator-associated pneumonia infection in burn intensive care unit was lower than the rates of intensive care units. However, as can be predicted, the burn infection rate of the patients who came to the burn intensive care unit was $45 \%$, and none in the other intensive care units. When we evaluate the microorganisms produced by the intensive care unit, there is no difference between the intensive care units in terms of the distribution of organisms.

According to the data about catheter location, infection type and number of antibiotics were not different between groups in terms of catheter locations. It has been reported in the literature that femoral catheter insertion increases the susceptibility to catheter-related infections due to the flora of the catheter site and difficulty in maintenance (11). In our study, we evaluated the only culture-positive patients, and we think that a study in which all patients with central venous catheters in intensive care unit will be evaluated, whether or not they are diagnosed with an infection, may have more critical and clinical consistency.

Many conditions affect mortality and morbidity in ICU patients. In a study conducted by Craven et al. in which the relationship between nosocomial infections and death was examined, the risk for mortality increased in some diseases (12). These have been reported as a neurological disease, cardiopulmonary arrest, acute respiratory failure, bacteremia, head trauma, multiple trauma, abdominal sepsis or trauma, respiratory disease, renal failure, acute myocardial infarction, and pulmonary edema. In our study, mortality was $82 \%$ in patients with one or more comorbidities and $25 \%$ in those without comorbidities. Ventilator-associated pneumonia was significantly higher in patients with comorbidities, whereas burn infections were higher in patients without comorbidities. This situation can be explained by the fact that burn patients form the majority of the patient group without the additional disease.

When the relationship between intubation and mechanical ventilation with ICU acquired infection was examined, mechanical ventilation was reported as a factor that increases the risk of purchased disease in the $\operatorname{ICU}(70,72)$. In our study, the duration of ICU stay was significantly longer in patients who were intubated or tracheotomized in admission to ICU than those admitted with ICU mask O2. Mortality was over $60 \%$ in intubated and tracheotomized patients and $18.5 \%$ in mask $\mathrm{O} 2$. When the relationship between airway status and type of infection was evaluated in ICU, the rate of catheter-related urinary tract infection $(0 \%)$, intubated $(8.8 \%)$, and tracheostomy $(20 \%)$ was lower in patients with mask $\mathrm{O}_{2}$ airway. Furthermore, as expected, the rate of ventilator-associated pneumonia infection $(0 \%)$, intubated $(23.2 \%)$, and tracheostomy $(50 \%)$ was significantly lower in patients with mask $\mathrm{O}_{2}$ airway than those admitted to intensive care. This situation suggests that intubation, mechanical ventilation, and tracheotomy are risk factors for ventilator-associated pneumonia and respiratory infections, as reported in the literature.

The admission diagnoses of the patients, the presence of immunosuppressive treatment, the exposure and resistance to infectious agents and the resistance to the infectious agents, and the determination of microorganisms and infection in different diagnostic groups also differ $(13,14)$. In a study conducted to determine predisposing factors for infections developing in the intensive care unit in our country, mortality was higher in patients with diabetes mellitus and renal failure, and the mortality rate was lower in patients hospitalized in an intensive care unit after surgical intervention compared with patients admitted to an intensive care unit for other reasons (15). In our study, patients were divided into diagnostic groups according to hospitalization diagnoses. The mean length of hospital stay was significantly longer in the patients who were followed up for neurological reasons. The mortality rate was nearly $100 \%$ in the patients followed up in the intensive care unit for neurological and gastrointestinal reasons, 32\% in burn patients, and $48 \%$ in trauma patients. The mean age of burn and trauma patients and the absence of concomitant diseases that increase morbidity and mortality may explain this situation.

We found that the lowest hospitalization time was observed in patients diagnosed as burn infection. The second lowest hospitalization time was in the laboratory-proven blood 
circulation infection group. When we evaluated the diagnostic groups in terms of mortality, mortality was found to be around $60 \%$ in all groups except the burn group. As the duration of the stay was short, mortality was significantly lower in the burn group (29\%).

In the literature, Acinetobacter species are reported to cause colonization of patients rapidly due to their widespread presence in hospital settings. It is said that the rate of colonization in the intensive care unit in the first week is approximately $70 \%$. Colonized or infected patients are a vital source for these bacteria, and infection development rate is higher in colonized patients $(26 \%)$ than non-colonized (5\%) patients. It is stated that these bacteria can create epidemics by passing from patient to patient or from environment to patient with their hands (16). Acinetobacter infection rate in our hospital is higher than other microorganisms is remarkable in our data.

\section{Conclusion}

In our study, retrospective evaluation of culture-positive infection cases in our intensive care units revealed that factors such as hospitalization diagnoses, presence of comorbidities, and percentage of burns were firmly related to the duration of intensive care hospitalization and mortality. The microorganisms isolated in our intensive care units were partially changing over the years, but we found that Acinetobacter baumannii infections were significantly higher than other organisms. Besides, we believe that individual infection diagnosisisolate and surveillance studies for their sub-units will be beneficial for the control of health-related infections.

\section{Compliance with Ethical Standards}

Conflict of Interest The authors declare that they have no competing interests.

Ethical Approval All applicable international, national, and/or institutional guidelines for the care and use of animals were followed.

Informed Consent Informed consent was obtained from all individual participants included in the study.

\section{References}

1. Vincent J-L, Jean-Louis V. Nosocomial infections in adult intensive-care units. Lancet. 2003;361(9374):2068-77.
2. Guillot C. Reported infection rates not tied to ICU mortality. Hospitalist News. 2010;3(6):3.

3. Huang SS, Septimus E, Kleinman K, et al. Targeted versus universal decolonization to prevent ICU infection. N Engl J Med. 2013;368(24):2255-65.

4. Mittal A. Surveillance of infection in ICU. Journal of Patient Safety \& Infection Control. 2015;3(2):111.

5. Alberti C, Brun-Buisson C, Burchardi H, Martin C, Goodman S, Artigas A, et al. Epidemiology of sepsis and infection in ICU patients from an international multicentre cohort study. Intensive Care Med. 2002;28(2):108-21.

6. El-Sahrigy SAF, Shouman MG, Ibrahim HM, et al. Prevalence and anti-microbial susceptibility of hospital acquired infections in two pediatric intensive care units in Egypt. Open Access Maced J Med Sci. 2019;7(11):1744-9. https://doi.org/10.3889/oamjms.2019.485.

7. Trebosc V, Gartenmann S, Tötzl M, et al. Dissecting colistin resistance mechanisms in extensively drug-resistant Acinetobacter baumannii clinical isolates. MBio. 2019;10(4). https://doi.org/10. 1128/mBio.01083-19.

8. Winterbottom F, Jenkins M. Infections in the intensive care unit: posttransplant infections. Crit Care Nurs Clin North Am. 2017;29(1):97-110. https://doi.org/10.1016/j.cnc.2016.09.002.

9. Velasquez Reyes DC, Bloomer M, Morphet J. Prevention of central venous line associated bloodstream infections in adult intensive care units: a systematic review. Intensive Crit Care Nurs. 2017;43: 12-22. https://doi.org/10.1016/j.iccn.2017.05.006.

10. Ertürk A, Cicek AC, Koksal E, et al. Microorganisms isolated from various clinical samples and their antibiotic susceptibilities in intensive care unit patients. Ankem Derg. 2012;26(1):1-9. https://doi. org/10.5222/ankem.2012.001.

11. Arvaniti K, Lathyris D, Blot S, et al. Cumulative evidence of randomized controlled and observational studies on catheter-related infection risk of central venous catheter insertion site in ICU patients: a pairwise and network meta-analysis. Crit Care Med. 2016;12(4):1458-63.

12. Craven DE, Kunches LM, Lichtenberg DA, et al. Nosocomial infection and fatality in medical and surgical intensive care unit patients. Arch Intern Med. 1988;148(5):1161-8.

13. Kolgelier S, Kucuk A, Demir NA, et al. Nosocomial infections in intensive care units: etiology and predisposing factors. Kafkas $\mathrm{J}$ Med Sci. 2012;2(1):1-5.

14. Kaya S, Oksuz H, Senoglu N, et al. Infection Surveillances in the Anesthesiology and Reanimation Clinic of Kahramanmaras Sutcu Imam University Medical Faculty Researching Hospital. The Eurasian Journal of Medicine. 2007;39(3):103-8.

15. Ece G, Adanır T. The evaluation of the distribution and antimcrobial susceptibility profile of the strains isolated at anesthesiology intensive care unit. J Clin Anal Med. 2014;5(4):320-3.

16. Sirin MC, Agus N, Yilmaz N, et al. The change of antibiotic resistance profiles over the years in Pseudomonas aeruginosa and Acinetobacter baumannii strains isolated from intensive care units. Journal of Clinical and Experimental Investigations. 2015;6(3): $279-85$.

Publisher's Note Springer Nature remains neutral with regard to jurisdictional claims in published maps and institutional affiliations. 